\title{
Warum werden Kopien für Kollegen nicht abgerechnet?
}

_ Die Nr. 40144 EBM ist eine Kostenpauschale für reproduzierte Befundmitteilungen, Berichte, Arztbriefe und andere patientenbezogene Unterlagen für andere Ärzte. Die Leistung ist mit 0,13 Euro bewertet und wird außerhalb des Regelleistungsvolumens (RLV) so ausbezahlt wie geltend gemacht. Wenn Sie also Berichte oder Befunde für einen Kolle-

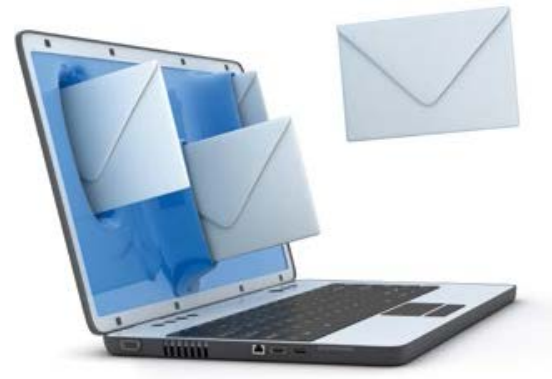

gen oder eine Klinik reproduzieren, ob mit dem Kopiergerät oder der EDV, können Sie diese Nr. für jede einzelne Seite ansetzen. Das gilt auch für Kopien, die für Nicht-Vertragsärzte, also Privatärzte, bestimmt sind. Eine Obergrenze gibt es nicht. Werden die Kopien per Fax oder E-Mail verschickt, kann zusätzlich die Nr. 40120 angesetzt werden - allerdings

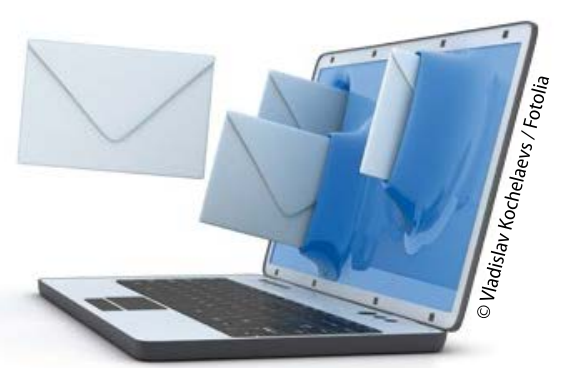

Kopieren und verschicken mit zwei Mausklicks - abrechnen kann man es trotzdem.

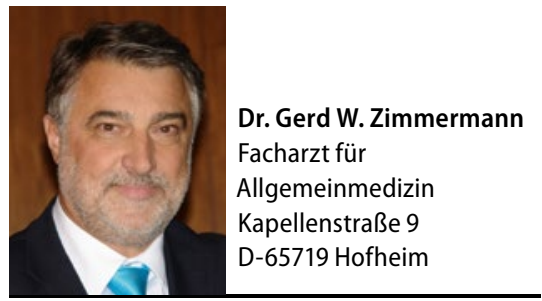

nur einmal, auch wenn mehrere Seiten gefaxt bzw. gemailt werden. Beim Postversand kommen die Pauschalen nach den Nrn. 40120-40126 je nach Umfang zum Ansatz.

\section{MMW-KOMMENTAR}

Die Nr. 40144 ist offensichtlich kaum bekannt, denn weniger als die Hälfte aller Vertragsärzte rechnet diese Pauschale ab. Damit generieren sie aber immerhin ein Honorarvolumen von ca. 3,5 Mio. Euro - der andere Teil der Ärzteschaft verschenkt also mutmaßlich eine Summe in gleicher Größenordnung. Kopien für den persönlichen Patientengebrauch können übrigens wegen der eindeutigen Leistungsbeschreibung nicht nach Nr. 40144 der Kasse in Rechnung gestellt werden, sondern sind privat mit 0,50 Euro pro Seite zu liquidieren.

\section{Auszahlungsschein wird in AU-Schein integriert}

_ Ab dem 1. Januar 2016 gibt es für die Bescheinigung der Arbeitsunfähigkeit (AU) - den „gelben Schein“ - und den Auszahlschein zum Bezug des Krankengeldes von der Krankenkasse nur noch ein Formular. Die Form der Krankschreibung ändert sich deshalb künftig nicht mehr ab der siebten AU-Woche. Der Auszahlschein für das Krankengeld wird in die klassische AU-Bescheinigung integriert. Die neue Bescheinigung ist bundesweit einheitlich und kann im Gegensatz zu den bisherigen Auszahlungsscheinen am Computer ausgefüllt oder auch per Blankoformularbedruckung erstellt werden. Alte Vordrucke dürfen nur noch bis 31. Dezember 2015 verwendet werden.

\section{MMW-KOMMENTAR}

Das neue Formular ähnelt stark der bisherigen AU-Bescheinigung, hat aber unten ein zusätzliches Feld „Im Krankengeldfall". Dort kann ab der siebten AU-Woche oder im sonstigen Krankengeldfall das Fortbestehen der Arbeitsunfähigkeit oder deren Ende (Endbescheinigung) durch Ankreuzen kenntlich gemacht werden. Neu sind auch Felder, auf denen die Diagnosen sowie die Einleitung besonderer Maßnahmen wie Rehabilitation oder stufenweise Wiedereingliederung angegeben werden können. Neu ist außerdem, dass der Patient künftig einen Durchschlag $\operatorname{der} A U$-Bescheinigung erhält mit dem Hinweis, dass für den Bezug von Krankengeld ein lückenloser Nachweis der AU erforderlich ist. Demnach muss sich der Patient bei Fortbeste- hen der AU spätestens an dem Werktag bei seinem Arzt vorstellen, der auf den letzten Tag $\operatorname{der} A U$-Bescheinigung folgt. Endet eine solche Bescheinigung z. B. am Freitag, muss der Patient den Arzt für eine Folgebescheinigung am darauffolgenden Montag aufsuchen. Die Anfrage zum Fortbestehen der AU (Formular 52) wird ebenfalls zum 1. Januar 2016 verändert. Es handelt sich dabei jedoch bloß um überwiegend sprachliche Anpassungen. Die neuen Vordrucke können ab Dezember 2015 bestellt werden. Sie sind ab Januar 2016 in die Praxissoftware integriert und werden mit dem Quartals-Update der Softwarehäuser bereitgestellt. Das Software-Update für das 1. Quartal 2016 sollte deshalb möglichst vor dem ersten Praxistag im neuen Jahr installiert werden. 